\title{
Morphological, structural and electrical properties of pentacene thin films grown via thermal evaporation technique
}

\author{
Fatin Nor Ahmad', Yusmar Palapa Wijaya², Khairul Anuar Mohamad ${ }^{3}$, Nafarizal Nayan ${ }^{4}$, Megat $^{2}$ \\ Muhammad Ikhsan Megat Hasnan ${ }^{5}$, Afishah Alias ${ }^{6}$, Bablu Kumar Ghosh ${ }^{7}$ \\ 1,2,3,4,5 Faculty of Electrical and Electronic Engineering, Universiti Tun Hussein Onn Malaysia, Malaysia \\ 1,2,3,4,5 Microelectronics and Nanotechnology-Shamsuddin Research Center (MiNT-SRC), Universiti Tun Hussein Onn \\ Malaysia, Malaysia \\ ${ }^{6}$ Faculty of Applied Science and Technology, Universiti Tun Hussein Onn Malaysia, Malaysia \\ ${ }^{7}$ Faculty of Engineering, Universiti Malaysia Sabah, Malaysia
}

\section{Article Info}

Article history:

Received Nov 11, 2020

Revised Mar 2, 2021

Accepted Apr 24, 2021

\section{Keywords:}

Electrical

Morphology

Pentacene

Thermal evaporation

Thin film

\begin{abstract}
The physical and structural characteristics of pentacene thin films on indium tin oxide (ITO)-coated glass were studied. The pentacene films were deposited using the thermal evaporation method with deposition times of 20, 30, and 60 minutes. Field-emission scanning electron microscopy (FESEM) images revealed that film thickness increased with deposition time, with a bulk phase layer appearing at 60 minutes. The presence of the thin-film phase corresponding to $15.5 \AA$ lattice spacing was demonstrated by X-ray diffraction (XRD) patterns in pentacene films with deposition times of 20 and 30 minutes. Meanwhile, with a deposition time of 60 minutes and a lattice spacing of $14.5 \AA$, the existence of the bulk phase was verified in the pentacene film. Atomic force microscopy (AFM) images of the crystallinity of the pentacene films revealed that the pentacene films deposited on ITO-coated glass exhibited the formation of similar islands with modular grains, results in a fine crystalline structure. From the current-voltage (I-V) and current density-voltage $(\mathrm{J}-\mathrm{V})$ characteristics, the pentacene films were ohmic and that current increased as the pentacene's thickness decreased. Pentacene films deposited on an ITO-coated glass substrate showed potential in the development of broadband and narrowband optoelectronic devices on a transparent substrate.
\end{abstract}

This is an open access article under the $\underline{C C B Y-S A}$ license.

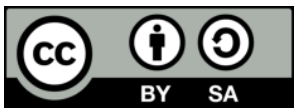

\section{Corresponding Author:}

Fatin Nor Ahmad

Faculty of Electrical and Electronic Engineering

Universiti Tun Hussein Onn Malaysia

86400, Parit Raja, Johor, Malaysia

Email: fatinnorahmad@gmail.com

\section{INTRODUCTION}

In this new era of science and technology, organic electronics is experiencing rapid growth in the tremendously exciting area of research and development in organic electronics. Organic molecular crystals are assembled from the intermolecular interaction with weak van der Waals forces, and multiple crystalline packaging states commonly exist in the active layer of a semiconductor device. Pentacene $\left(\mathrm{C}_{22} \mathrm{H}_{14}\right)$ is one of the p-type organic semiconductor materials that are widely used in the optical and electronics fields. It is a polycyclic aromatic hydrocarbon made up of five fused benzene rings with the appearance of purple or deep blue solid color in powder form. Nevertheless, when pentacene is exposed to light, air, or chemicals, it will change to green color due to degradation. Pentacene's crystalline structure is triclinic, involving thin-film, 
bulk, and single-crystal phases [1]. When ultraviolet (UV) or visible light is absorbed, the compound will be excited. When the number of acene rings increases, the bandgap of pentacene decreases and the temperature increases. Pentacene has unique properties compared with other linear acenes, such as benzene, naphthalene, anthracene, tetracene, hexacene, and heptacene. Among organic materials, pentacene thin films exhibit the highest mobility of up to $35 \mathrm{~cm}^{2} / \mathrm{Vs}$ [2]-[5] in transistors, lending to their potential application in inexpensive electronic devices due to their low cost [6], flexibility, large area, light weight, and low-temperature processing [7]-[9]. These materials are deposited on various substrates including silicon, transparent plastic, and glass. The fabrication of optoelectronic devices on transparent substrates such as, glass or indium tin oxide (ITO)-coated glass, is attracting interest for applications in photo- detectors and photo-multiplications for broadband and narrowband response-ability using organic-only or organic-inorganic heterojunction diode structures.

There are a number of deposition processes for growing pentacene thin films. From reported studies, pentacene thin films are mostly grown using physical deposition, such as thermal evaporation [7], [10]-[14], pulsed laser deposition (PLD) [15], [16], and organic molecular beam deposition (OMBD) [16], whereas chemical deposition, such as ink-jet printing, dip coating [17], and solution-based spin coating [18], depends on preparation conditions and the material's nature. The physical evaporation techniques operate by changing the phase of the pentacene from a solid phase to the vapor phase and converting again to a solid phase on the substrate. Meanwhile, chemical deposition is strongly dependent on the chemistry of the solution, $\mathrm{pH}$ value, and viscosity. Soluble pentacenes, such as 6,13-bis(triisopropylsilylethynyl) pentacene, also known as TIPSpentacene, have gained consideration for the deposition of thin films from solutions. The selection of technique will affect the film's quality and the overall appearance on the substrate [19].

This work reports the processes involved in the deposition of pentacene thin films via thermal evaporation, emphasizing on the inorganic conductive oxides with a transparent substrate. The influence of deposition time and film thickness with constant pentacene's weight and vacuum pressure was discussed on the morphological and structural properties of pentacene films. Finally, we investigated the electrical properties of the pentacene thin films with varying deposition times using a metal-organic metal structure for the development of a heterojunction configuration of pentacene and conductive oxide for photo-diode applications.

\section{RESEARCH METHOD}

Figure 1 shows the flowchart of the deposition process of pentacene thin films on ITO-coated glass using the thermal evaporation technique. Pentacene powder (Sigma-Aldrich) was used without any other further purification. The substrate was an ITO-coated glass with sheet resistance of $10 \Omega / \mathrm{sq}$ cut into $1.5 \mathrm{~cm} \times 2 \mathrm{~cm}$. The ITO-coated glass substrate was rinsed with acetone, methanol, and deionized water using ultrasonic bath for 10 minutes in $50 \mathrm{ml}$ of each solution. Then, the substrates was dried slowly at room temperature using an air dust blower.

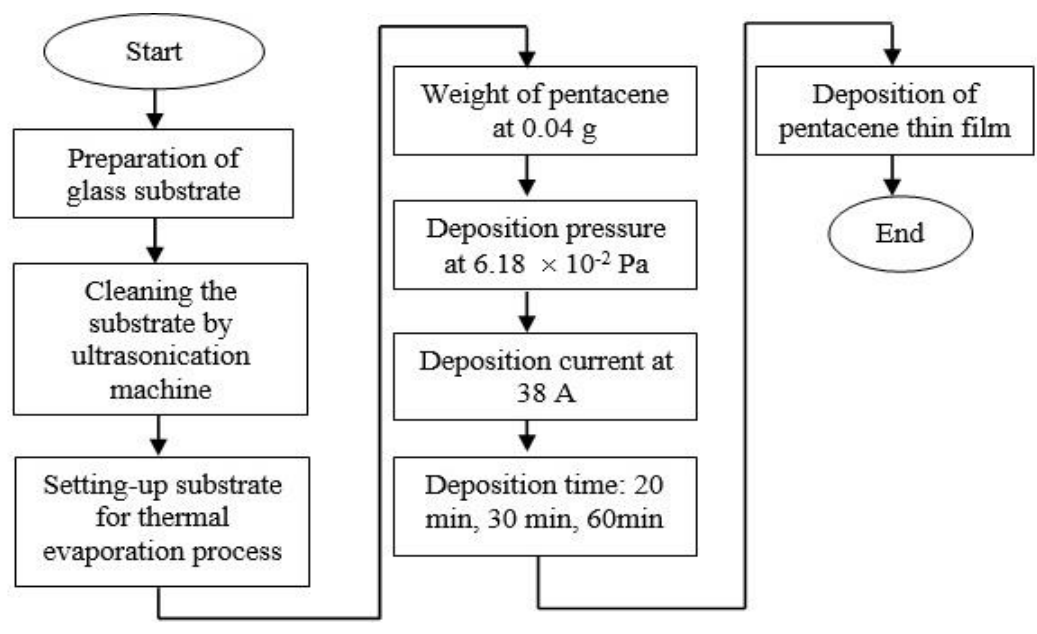

Figure 1. Flowchart of pentacene thin film's deposition process

Pentacene in a solid or powder form was deposited on the ITO-coated glass using a thermal evaporator system (Ulvac Kiko: VPC-061), as shown in Figure 2(a). The distance between the pentacene 
powder in a tungsten boat and the substrate holder was about $10 \mathrm{~cm}$. The applied current was kept constant at $38 \mathrm{~A}$ for each deposition time of $20 \mathrm{~min}, 30 \mathrm{~min}$, and $60 \mathrm{~min}$ to optimize the condition of the thin films at room temperature. The vacuum system's pressure and the pentacene's powder weight were $6.18 \times 10^{-2} \mathrm{~Pa}$ and $0.04 \mathrm{~g}$, respectively. For electrical characterization, the top-contact was aluminium ( $\mathrm{Al})$. An $\mathrm{Al}$ wire was placed on the tungsten boat and deposited using thermal evaporation onto the pentacene thin film. Figure 2(b) shows the metal-organic-metal structure with pentacene thin film as an active layer.

The thickness of the pentacene thin film was measured using field-emission scanning electron microscopy (FESEM) (JEOL JSM-7600F) with a $15 \mathrm{kV}$ accelerating voltage through the FESEM crosssection. X-ray diffraction (XRD) was used to measure the structure of the pentacene thin film using $\mathrm{Cu} \mathrm{K \alpha}$ radiation $(\lambda=0.154060 \mathrm{~nm})$ and analyzed using HighScore software. The $2 \theta$ range was $5^{\circ}-40^{\circ}$ with slit $=1 / 2$ omega $0.5^{\circ}$. Atomic force microscopy (AFM) was used using a contact mode to examine the morphology of the grains of the pentacene on ITO-coated glass. The scan size was $1 \mu \mathrm{m}$ and the scan was analyzed using Spisel32 software. Meanwhile, the current-voltage (I-V) and current density-voltage (J-V) measurement of the metal-pentacene-metal structure was carried out using Oriel Sol1A software.
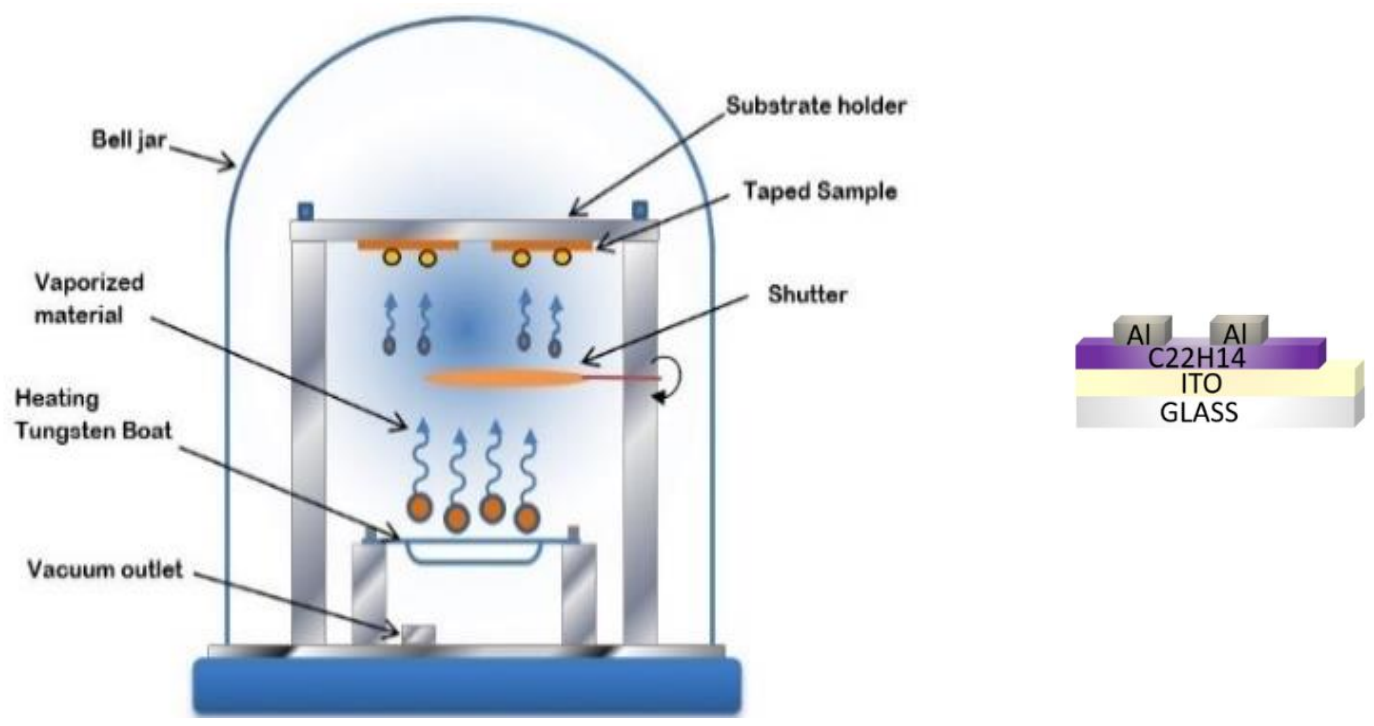

(a)

(b)

Figure 2. Schematic diagrams of, (a) Pentacene deposited using thermal evaporation, (b) Metal-organic-metal structure with pentacene thin film as an active layer

\section{RESULTS AND DISCUSSION}

\subsection{Characteristics of film thickness}

Figure 3(a)-3(c) depict cross-sections of FESEM images of pentacene thin films at three deposition times. FESEM images revealed that film thickness increased with increasing deposition times from 20 min to $30 \mathrm{~min}$ and $60 \mathrm{~min}$. The deposition time affected the thickness of the pentacene thin films. Figure 3(c) shows that another layer was detected, with a thickness of $131 \mathrm{~nm}$, which was the bulk phase changing from the thin-film phase [1]. Figure 3(d) shows the relationship between deposition time and the thickness of the thin film. Thus, thickness increased gradually from $356 \mathrm{~nm}$ to $452 \mathrm{~nm}$ and $581 \mathrm{~nm}$ when the time for the evaporation process increased [20]. The longer deposition time revealed a thicker pentacene thin film.

\subsection{Characteristics of the pentacene structure}

Interestingly, Figure 4 reveals the presence of X-ray diffraction (XRD) patterns for pentacene thin films grown on ITO-coated glass with different deposition times. The films exhibited one phase with a peak of diffraction of the first order at $5.78^{\circ}$, corresponding to $15.5 \AA$ of lattice spacing, which confirmed the thinfilm phase. Furthermore, XRD indicated a second spacing of a second phase at a diffraction angle of $6.18^{\circ}$, corresponding to the lattice spacing of $14.5 \AA$. This pattern showed the presence of pentacene in the bulk phase. It showed five polymorphs, labeled as the triclinic crystalline phase, for the pentacene deposits on the ITO-coated glass substrate. $(00 k)$ represents the thin-film phase, while $\left(00 k^{\prime}\right)$ represents the bulk phase. The pentacene thin film only possessed crystallinity on the (001) plane at deposition time of 20 min and 30 min.

Morphological, structural and electrical properties of pentacene thin films grown via... (Fatin Nor Ahmad) 


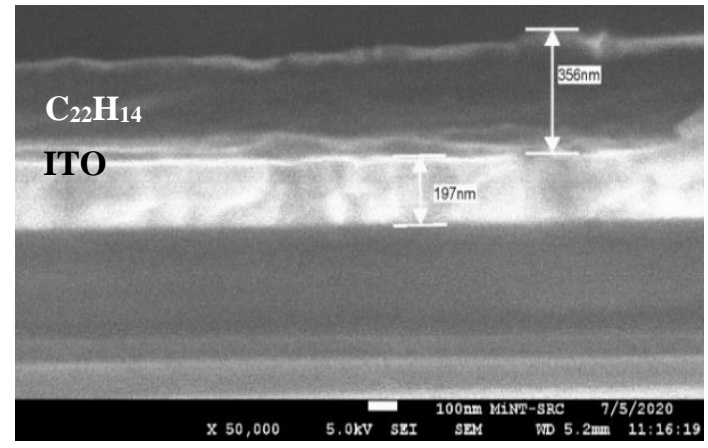

(a)

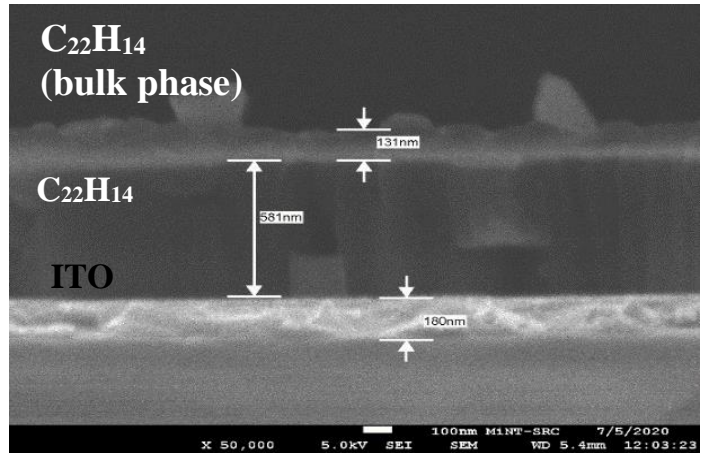

(c)

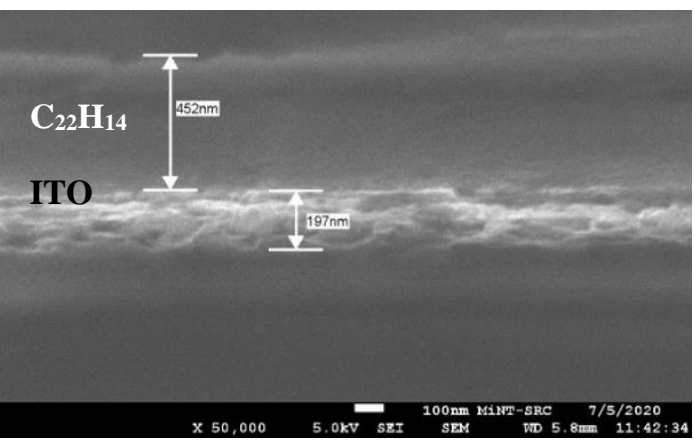

(b)

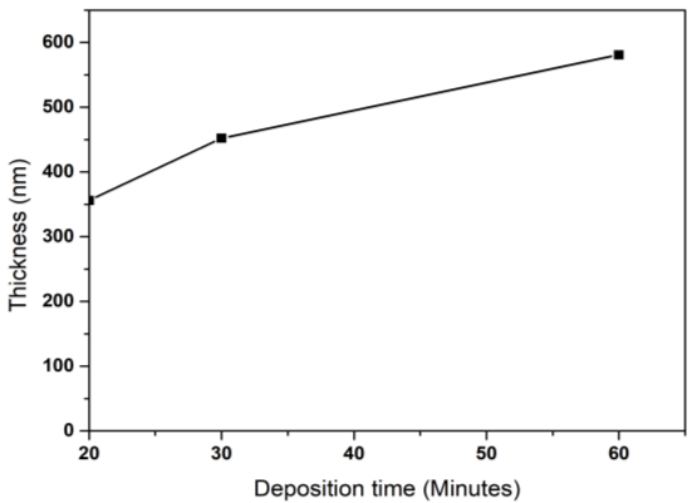

(d)

Figure 3. Cross-section of pentacene thin film at deposition time of, (a) $20 \mathrm{~min}$, (b) $30 \mathrm{~min}$, and (c) $60 \mathrm{~min}$, and (d) Relationship between deposition time and thickness of pentacene thin film

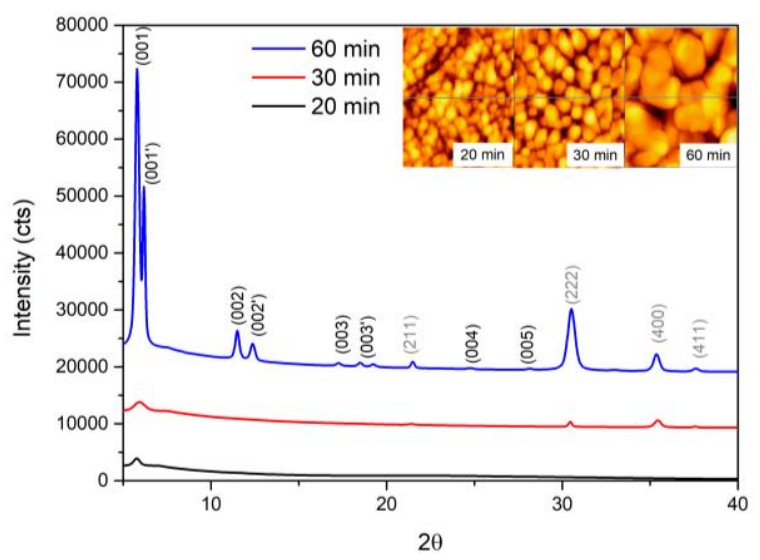

Figure 4. XRD patterns of pentacene thin film grown on ITO-coated glass with deposition time of $20 \mathrm{~min}$ (black line), $30 \mathrm{~min}$ (red line), and $60 \mathrm{~min}$ (blue line). The inset shows the AFM result

However, deposition time of 60 min indicated a thin-film phase with crystallinity on the (001), (002), (003), (004), and (005) planes, and bulk phase on the (001'), (002'), and (003') planes. The bulk phase appeared by increasing the deposition time of the pentacene. When thickness increased, there was a transition from the thin-film phase to the bulk phase due to the pentacene grains being mixed by the process of reevaporation. The presence of the bulk phase strengthened the adhesion of the pentacene to the ITO-coated glass. This is also evident in other studies, which reported that the bulk phase assists the pentacene layer in its 
nucleation [13]. Nevertheless, both thin-film and bulk phases are crystalline and firmly structured. The crystalline size, D, for each peak of pentacene with different deposition times included in Table 1 by using Debye-Scherrer formula [21],

$$
\mathrm{D}=\frac{0.9 \lambda}{\beta \cos \theta}
$$

where $\lambda$ is the wavelength of the $X$-ray radiation used $(0.15406 \mathrm{~nm}), \beta$ is the full width at half maximum (FWHM), and $\theta$ is the Bragg's diffraction angle of the main peak in the XRD spectra. However, the XRD peak can be widened through the defects and internal stress, so these obtained crystalline size values are comparable to the other reported values in the literature [22]-[26].

Table 1. Difference deposition time between XRD result of pentacene on ITO-coated glass

\begin{tabular}{cccccc}
\hline Deposition time & $h k l$ & $2 \theta\left(^{\circ}\right)$ & FWHM & Crystalline size $(\mathrm{nm})$ & References \\
\hline $20 \mathrm{~min}$ & 001 & 5.7674 & 0.432 & 1.377 & {$[22]$} \\
$30 \mathrm{~min}$ & 001 & 5.9398 & 0.720 & 1.337 & {$[22]$} \\
& 001 & 5.7824 & 0.2657 & 1.374 & {$[22]$} \\
& 001 & 6.1703 & 0.1476 & 1.288 & {$[23]$} \\
& 002 & 11.4772 & 0.2657 & 0.692 & {$[22]$} \\
$60 \mathrm{~min}$ & 002 & 12.3535 & 0.2952 & 0.643 & {$[23]$} \\
& 003 & 17.2451 & 0.2952 & 0.460 & {$[24]$} \\
& 003 & 18.4742 & 0.2952 & 0.430 & {$[25]$} \\
& 004 & 24.7306 & 0.3542 & 0.321 & {$[26]$} \\
\hline
\end{tabular}

The AFM result shows the growth condition of the pentacene thin films using a scan size of $1 \times 1 \mu \mathrm{m}^{2}$. It has small changes in film morphology with various deposition times. The pentacene films were well deposited for all deposition times but not homogenous due to the bulk phase of the pentacene grains. As verified in the XRD measurement, the bulk phase only emerged in the deposition time of 60 min due to the nucleation of the pentacene layer. From the overall AFM images, pentacene films deposited on ITO-coated glass exhibited a similar island formation with modular grains without visible dendrite crystallinity. The relationship between grain size and surface roughness is formed as Figure 5. The result indicates that as the pentacene film's roughness gradually increased, the grain size slowly increased; thus, the large grain size gave a fine crystalline structure for the pentacene film [10]. By increasing the deposition time, the roughness and grain size increased, with a better crystalline structure. The different roughness and grain size of pentacene on the ITO substrate indicated that the surface energy affected the film deposited at different deposition times.

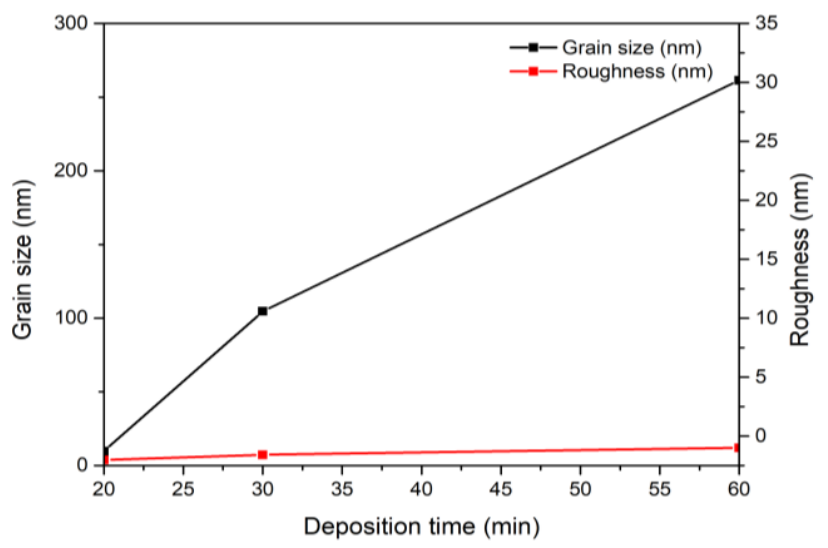

Figure 5. Relationship of grain size and surface roughness for $20 \mathrm{~min}, 30 \mathrm{~min}$, and $60 \mathrm{~min}$ of deposition time

\subsection{Electrical characteristics of the pentacene thin film}

The electrical characteristics of an $\mathrm{Al} /$ pentacene/ITO structure with three thicknesses of $356 \mathrm{~nm}$, $452 \mathrm{~nm}$, and $712 \mathrm{~nm}$ are provided in Figure 6. The Al/pentacene/ITO with $356 \mathrm{~nm}$ thickness revealed a rectification characteristic. The I-V curve changed to ohmic behavior for structures with $452 \mathrm{~nm}$ and $712 \mathrm{~nm}$ thicknesses, as shown in Figure 6(a) [28]. As the tip was forced harder into the sample, conductance 
increased. From the resistivity measurement using the gradient of the I-V curve, the trend of the pentacene thin film's resistivity showed an increase with the increase of the pentacene thin film's thickness. The resistivity values were $1.72 \times 10^{10}, 2.61 \times 10^{10}$, and $3.45 \times 10^{11} \Omega . \mathrm{cm}$ for pentacene thickness of 356,452 , and $712 \mathrm{~nm}$, respectively. The relationship between current density as a function of the pentacene's thickness is presented in Figure 6(b). Current density increased when the thickness was thinner with increasing forward-bias voltage.

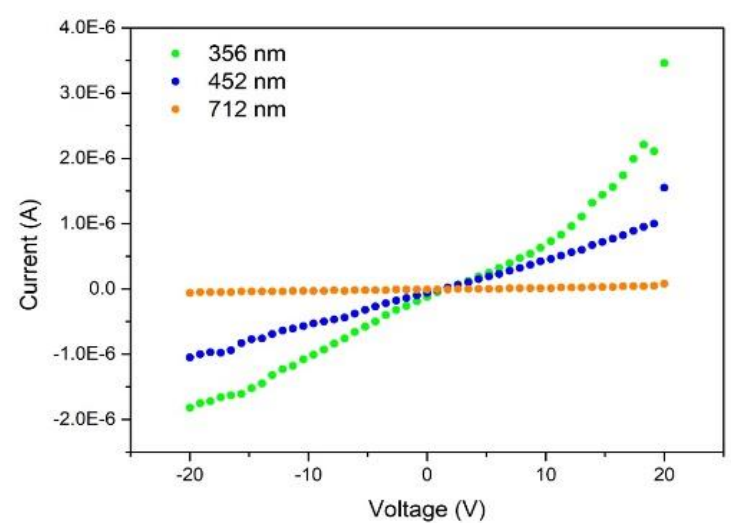

(a)

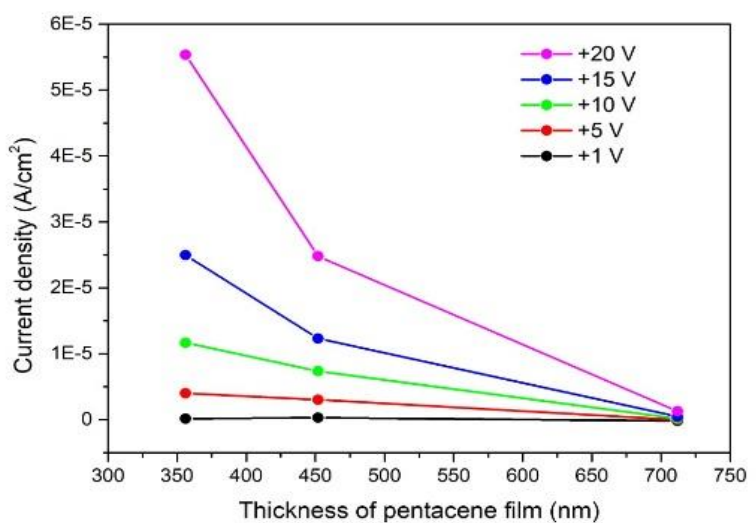

(b)

Figure 6. These figures are, (a) Current-voltage characteristics, (b) Current density as a function of the thickness

Furthermore, current density can be determined from equation

$$
\mathrm{J}=\frac{\mathrm{I}}{\mathrm{A}}
$$

where the largest current density of about $5.52 \times 10-5 \mathrm{~A} / \mathrm{cm}^{2}$ was obtained for voltage bias of $+20 \mathrm{~V}$ with $356 \mathrm{~nm}$ of thickness.

\section{CONCLUSION}

In summary, the pentacene's morphological and structural studies were done with deposition time of $20 \mathrm{~min}, 30 \mathrm{~min}$, and $60 \mathrm{~min}$ using thermal evaporation. A longer deposition time of $60 \mathrm{~min}$ resulted in the formation of similar islands with modular grains on the pentacene thin film compared with 20 min and 30 min of deposition time. A comparison of the third-, fourth-, and fifth-order diffraction peaks revealed a higher diffraction intensity for pentacene thin film on ITO-coated glass and the presence of thin-film and bulk phases. Grain size and surface roughness increased as deposition time increased. The electrical characteristics of the metal/pentacene/metal structure revealed changes from the rectification to the ohmic behavior as the pentacene's thickness increased. In addition, current density was influenced by the nature of the pentacene thin film. Thus, deposition time is an essential parameter in determining the molecular orientation and the electrical characteristics of pentacene for two-terminal device performance.

\section{ACKNOWLEDGEMENTS}

This work is supported by the Ministry of Higher Education Malaysia under the Fundamental Research Grant Scheme (FRGS/1/2018/TK10/UTHM/03/7) and Universiti Tun Hussein Onn Malaysia (UTHM) under Postgraduate Research Grant (GPPS) (H568) fund.

\section{REFERENCES}

[1] N. Shioya, R. Murdey, K. Nakao, H. Yoshida, T. Koganezawa, K. Eda, T. Shimoaka, and T. Hasegawa, “Alternative Face-on Thin Film Structure of Pentacene," Sci. Rep., vol. 9, no. 1, pp. 1-7, 2019, doi: 10.1038/s41598-01837166-6. 
[2] L. Jones and L. Lin, "An in Silico Study on the Isomers of Pentacene: The Case for Air-Stable and Alternative C22H14 Acenes for Organic Electronics," J. Phys. Chem. A, vol. 121, no. 14, pp. 2804-2813, 2017, doi: 10.1021/acs.jpca.6b11770.

[3] D. Li, S. H. Yu, and H. L. Jiang, "From UV to Near-Infrared Light-Responsive Metal-Organic Framework Composites: Plasmon and Upconversion Enhanced Photocatalysis," Adv. Mater., vol. 30, no. 27, pp. 1-7, 2018, doi: 10.1002/adma.201707377.

[4] A. Irfan, M. Imran, R. Thomas, M. A. R. Basra, S. Ullah, A. G. Al-Sehemi, and M. A. Assiri., "Exploring the effect of oligothiophene and acene cores on the optoelectronic properties and enhancing p- and n-type ability of semiconductor materials," J. Sulfur Chem., vol. 42, no. 2, pp. 180-192, 2020, doi: 10.1080/17415993.2020.1830401.

[5] M. K. Biddinika and S. Ohmi, "The Humidity Dependence of Pentacene Organic Metal-Oxide-Semiconductor Field-Effect Transistor," TELKOMNIKA Telecommunication, Computing, Electronics and Control, vol. 15, no. 2, pp. 578-583, 2017, DOI:10.12928/TELKOMNIKA.v15i2.5834.

[6] B. K. Ghosh, A. I. A. Rani, K. A. Mohamad, and I. Saad, "Low Leakage Current by Solution Processed PTAAZnO Transparent Hybrid Hetero-Junction Device," Electron. Mater. Lett., vol. 16, no. 5, pp. 457-465, 2020, doi: 10.1007/s13391-020-00235-y.

[7] K. M. Wibowo, M. Z. Sahdan, and N. Nayan, "Effect on Structural and Morphological Properties of Aluminum Thin Film At Different Substrates Deposited By Vacuum Thermal Effect on Structural and Morphological Properties of Aluminum Thin Film At Different Substrates Deposited By Vacuum Thermal Evaporation," Proc. of Science, Engineering \& Nanotechnology, pp. 16-19, 2018.

[8] S. Liu, P. Billig, A. Al-shadeedi, and V. Kaphle, "Doped bottom-contact organic field-effect transistors," Nanotechnology, vol. 29, no. 284001, 2018.

[9] N. A. Elgeme and S. Soued, "A pentacene -based organic MIS structures,” Energy Procedia, vol. 162, pp. 231-240, 2019, doi: https://doi.org/10.1016/j.egypro.2019.04.025.

[10] G. F. Salem, E. A. A. El-shazly, A. A. M. Farag, and I. S. Yahia, "Spectrophotometric investigations of optical linearity and nonlinearity of pentacene/ITO nanostructure thin film," Opt. - Int. J. Light Electron Opt., vol. 174, no. August, pp. 221-233, 2018, doi: 10.1016/j.ijleo.2018.08.018.

[11] S. Zhou, M. Li, Q. Tang, Z. Song, Y. Tong, and Y. Liu, "Deposition of Pentacene Thin Film on Polydimethylsiloxane Elastic Dielectric Layer for Flexible Thin-Film Transistors," IEEE Electron Device Lett., vol. 38, no. 8, pp. 1031-1034, 2017, doi: 10.1109/LED.2017.2714845.

[12] S. Pachmajer, A. O. F. Jones, M. Truger, C. Röthel, I. Salzmann, O.Werzer and R. Resel, "Self-Limited Growth in Pentacene Thin Films," ACS Appl. Mater. Interfaces, vol. 9, no. 13, pp. 11977-11984, 2017, doi: 10.1021/acsami.6b15907.

[13] C. Y. Han, Y. X. Ma, W. M. Tang, X. L. Wang, P. T. Lai, "A Study on Pentacene Organic Thin-Film Transistor with Different Gate Materials on Various Substrates," IEEE Electron Device Letters, vol. 38, no. 6, pp. 744--747, 2017, doi: 10.1109/LED.2017.2695538.

[14] P. Sagan, O. Aksimentyeva, G. Wisz, B. Tsizh, I.Virt, I. Rudy and M. Fruginsky, "The pentacene films on the glass / ITO surface : structure and optical properties,” Mol. Cryst. Liq. Cryst., vol. 671, no. 1, pp. 148-155, 2019, doi: 10.1080/15421406.2018.1542097.

[15] A. Pereira, S. Bonhommeau, S. Sirotkin, S. Desplanche, M. Kaba, C. Constantinescu, A. K. Diallo, D. Talaga, J. Penuelas, C. Videlot-Ackermann, A. Alloncle, P. Delaporte, and V. Rodriguez, "Morphological and crystalline characterization of pulsed laser deposited pentacene thin films for organic transistor applications," Appl. Surf. Sci., vol. 418, pp. 446-451, 2017, doi: 10.1016/j.apsusc.2017.01.281.

[16] D. Lubert-Perquel, D. K. Kim, P. Robaschik, C. W. M. Kay, and S. Heutz, "Growth, morphology and structure of mixed pentacene films," J. Mater. Chem. C, vol. 7, no. 2, pp. 289-296, 2019, doi: 10.1039/C8TC05525D.

[17] J. H. Lee, Y. Seo, Y. D Park, J. E. Anthony, D. H Kwak, J. A Lim, S. Ko, H. W Jang, K. Cho, and W. H Lee, "Effect of Crystallization Modes in TIPS-pentacene/Insulating Polymer Blends on the Gas Sensing Properties of Organic Field-Effect Transistors," Scientific Reports, vol. 9, no. 21, pp. 1-9, 2019, doi: 10.1038/s41598-01836652-1.

[18] A. C. Lokhande, R. B. V. Chalapathy, M. He, E. Jo, M. Gang, S. A. Pawar, C. D. Lokhande, and J. H. Kim, "Development of $\mathrm{Cu} 2 \mathrm{SnS} 3$ (CTS) thin film solar cells by physical techniques: A status review," Sol. Energy Mater. Sol. Cells, vol. 153, pp. 84-107, 2016, doi: 10.1016/j.solmat.2016.04.003.

[19] R. B. Mahewar, R. R. Vidule, and L. S. Ravangave, "Structure, morphology and optical parameters of spray deposited CZTS thin films for solar cell applications," Indian J. Sci. Technol., vol. 13, no. 21, pp. 2149-2156, 2020, doi: 10.17485/IJST/v13i21.642.

[20] N. A. Raship, S. N. M. Tawil, K. Ismail, N. Nayan, M. Tahan, and A. S. Bakri, "Effect of Deposition Time on Gd doped ZnO using Simultaneous RF and DC Sputtering," Proc. 2019 IEEE Reg. Symp. Micro Nanoelectron. RSM 2019, pp. 38-41, 2019, doi: 10.1109/RSM46715.2019.8943509.

[21] A. Huttner, T. Breuer, and G. Witte, "Controlling Interface Morphology and Layer Crystallinity in Organic Heterostructures : Microscopic View on C 60 Island Formation on Pentacene Buffer Layers," ACS Appl. Mater. Interfaces, vol. 11, pp. 35177-35184, 2019, doi: 10.1021/acsami.9b09369.

[22] A. K. Anbalagan, C. Jao, M. Syabriyana, C. Fan, S. Gupta, M. Chaudhary, Y. Chueh, N. Tai and C. Lee, "Influence of gamma-ray irradiation and post-annealing studies on pentacene films: the anisotropic effects on structural and electronic properties," Royal Society of Chemistry, pp. 14504-14510, 2020, DOI: 10.1039/D0RA04522E. 
[23] X. Zhang, M. Li, C. D. Agnese, G. Chen, X. Wang, and T. Miyasaka, "Thermo-evaporated pentacene and perylene as hole transport materials for perovskite solar cells," Dye and Pigment, vol. 160, pp. 285-291, 2019, doi: 10.1016/j.dyepig.2018.07.053.

[24] M. Jang, S. K. Kim, J. Lee, S. Ji, W. Song, S. Myung, J. Lim, S. S. L.ee, H. Jung, J. Lee, and K. An, “Amplifying gas sensor performance by embedding a cellulose-based buffer layer in organic transistors $\dagger$," Journal of Materials Chemistry C, pp. 21092-21099, 2019, doi: 10.1039/C9TC04889H.

[25] M. L. Mota, B. Rodriguez, A. Carrillo, R. C. Ambrosio, P. A. Luque, M. Mireles, I. Vivaldo, and M. A. Quevedo, "Fast and inexpensive synthesis of pentacene with high yield using 6, 13-pentacenequinone as precursor," J. Mol. Struct., vol. 1154, pp. 511-515, 2018, doi: 10.1016/j.molstruc.2017.10.070.

[26] D. K. Kim and S. Heutz, "Comparison of organic and inorganic layers for structural templating of pentacene thin films $\dagger$," Materials Horizons, 2019, doi: 10.1039/C9MH00355J.

[27] M. S. Mahdi, K. Ibrahim, A. Hmood, N. M. Ahmed, and A. Azzez, "A highly sensitive flexible SnS thin film photodetector in the ultraviolet to near infrared prepared by chemical bath deposition," RSC Advances, pp. 114980 114988, 2016, doi: 10.1039/C6RA24491B.

[28] W. Khaldi, A. Boubaker, A. Nasri, K. Lmimouni, and A. Kalboussi, "Electrical study of pentacene-based metalsemiconductor-metal structure: Schottky barrier and active layer thickness effects," IEEE Trans. Electron Devices, vol. 65, no. 11, pp. 5009-5013, 2018, doi: 10.1109/TED.2018.2869537.

\section{BIOGRAPHIES OF AUTHORS}

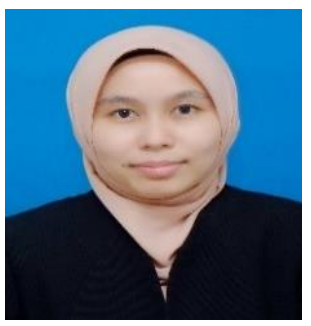

Fatin Nor Ahmad received a Bachelor of Engineering (Honours), Electronic Engineering in 2018 at Universiti Malaysia Perlis. She is a graduate member of the Board of Engineer Malaysia (BEM) since 2019. Currently, she is a master's student and graduates research assistant at the Faculty of Electrical and Electronic Engineering (FKEE) and Microelectronic and Nanotechnology-Shamsuddin Research Center (MiNT-SRC), Universiti Tun Hussein Onn Malaysia (UTHM).

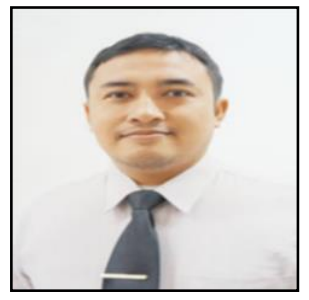

Yusmar Palapa Wijaya, He graduated with his bachelor (S.Si) in Physics from University Gadjah Mada, Yogyakarta in 2001 and received his master (M.T) from Electronics and Electrical Engineering from University Indonesia, Jakarta and master of science engineering (M.Sc.Eng) from Univeriste Bretagne Occidentale, France in 2011. He joined the Electronics Engineering Department of Polytechnic Caltex Riau, Pekanbaru, Indonesia in 2002 and currently a $\mathrm{PhD}$ student and Research Assistant at MiNT-SRC and Faculty Electrical and Electronics Engineering University Tun Hussein Onn.

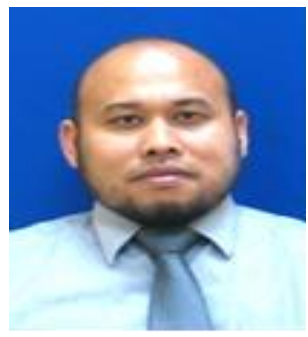

Khairul Anuar Mohamad received a Bachelor of engineering from the University of Electrocommunications, Japan (2001) and a Master of Science in Microelectronics from the University of Newcastle upon Tyne, UK (2004). He received the Doctor of Engineering (Dr.Eng) from Muroran Institute of Technology, Japan (2011). He joined Universiti Malaysia Sabah in 2002 and was promoted to Senior Lecturer position in 2011. He also a member of IEEE and IET and a graduate member of the Board of Engineer Malaysia (BEM) since 2008. Currently, he is working at Universiti Tun Hussein Onn Malaysia starting from 2017 and appointed as a principal researcher at Microelectronic and Nanotechnology-Shamsuddin Research Center in 2019.

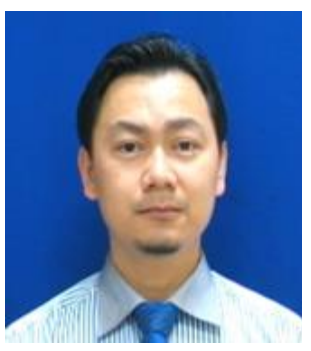

Nafarizal Nayan received bachelor's, master's, and Doctor of Engineering degrees in electronics engineering from Nagoya University, Japan. He is an Associate Professor in the field of plasma processing and nanoscale imaging and analysis with the Faculty of Electrical and Electronic Engineering, Universiti Tun Hussein Onn Malaysia, where he has been since April 2005, before he is appointed Director at Institute for Integrated Engineering of UTHM. He was formerly the Head of the Centre of Excellence known as Microelectronic and NanotechnologyShamsuddin Research Centre. 

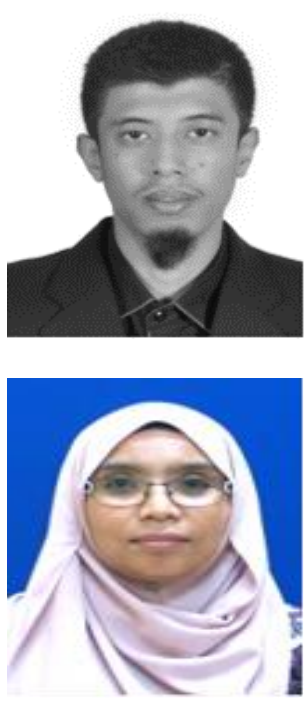

Megat Muhammad Ikhsan Megat Hasnan received the Degree of Bachelor of Telecommunication Engineering and the Master Degree of Eng. Sci. in microelectromechanical (MEMs) Design, from University of Malaya, Malaysia, in 2011 and 2015. He finished pursuing the Ph.D. Eng. Sci. in renewable energy at the same university in 2019. Currently, he is a postdoctoral fellow at University Tun Hussein Onn Malaysia, Malaysia at the Faculty of Electrical and Electronic Engineering.

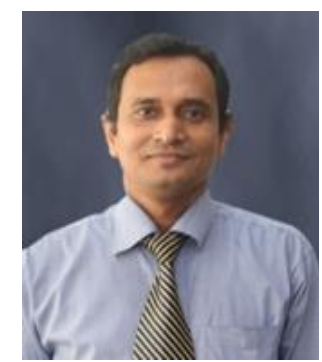

Afishah Alias received her B.Eng (Hons) in Electronics Engineering from University of Electrocommunications, Tokyo, Japan in 2001 and MSc from University Malaysia Sabah (UMS) specializing in Physics in 2008. In 2011, she received her Doctorate from Muroran Institute of Technology, Hokkaido, Japan specializing in Transparent Conductive Oxide. She has been a full-time lecturer at University Malaysia Sabah (UMS) since 2006 and is promoted as a Senior Lecturer in 2011. Currently, she is working at Universiti Tun Hussein Onn Malaysia starting in 2017.

Bablu Kumar Ghosh has received his Doctor of Engineering from Fukui University, Japan from the Graduate School of Engineering in 2004 under the "MONBUSHO" Scholarship. Currently, he is working in the Electrical and Electronic Engineering program under the Faculty of Engineering at University Malaysia Sabah as a senior lecturer. He was engaged as Radio Engineer, Scientific Officer, and Microwave system Engineer in Bangladesh. He also attended several conferences in the USA, Japan, China, Indonesia, and Malaysia. He is the author of about (40) Journals and conference papers. He also wrote an e-book on advanced materials technology for optoelectronic applications. 